\title{
Microstructural and Mechanical Characterization of Steel 2, 25Cr-1Mo Treated by Quenching \\ Process
}

Juliermes $C P^{1,2,3^{*}}$, Vitor $L S^{4}$, Ayrton $S B^{2}$, Luís $P M S^{3}$, Renata $B^{5}$ and José $F R S^{2}$

${ }^{1}$ Materials Science Laboratory, UEMA/CESC, Brazil

${ }^{2}$ Mechanical Testing Laboratory, PPGEM/IFPI CEP, Brazil

${ }^{3}$ Department of Metallurgical and Materials Engineering, UFC, Brazil

${ }^{4}$ Department of Materials Engineering, DEMa CEP, Brazil

${ }^{5}$ Technology Center, PPGCM-UFPI, Brazil

\begin{abstract}
Summary
Cr-Mo family steels are widely applied in the petrochemical industry, subjected to creep, may have their mechanical properties degraded in service, undergoing changes in their microstructure, therefore, understanding the heat treatment routes of these materials is of great relevance to good mechanical performance is obtained. This research aimed to investigate the influence of Quenching heat treatment on the microstructure and mechanical properties of the $2.25 \mathrm{Cr}-1 \mathrm{Mo}$ steel. For this, specimens were heated to $1,223 \mathrm{~K}$ in an argon atmosphere for $2 \mathrm{~h}$ and cooled in mineral oil. The microstructural characterization showed a predominance of the martensitic phase, $X R D$ analyzes identified $M_{7} C_{3}, M_{23} C_{6}$ and $M_{6} C$ carbides in the grain boundaries. Vickers microhardness tests showed that treated samples raised their hardness to $388 \mathrm{HV}$ and tensile tests confirmed that the heat treatment optimized the mechanical performance of the steel at temperatures of 300,773 and $873 \mathrm{~K}$.
\end{abstract}

\section{Keywords}

Steel 2.25Cr-1Mo, Quenching, Microstructure, Hot traction

\section{Introduction}

Chromium-Molybdenum steels are materials that operate at high pressures and high temperatures, mainly in the petrochemical industries and in the power generation area, this is due to their good corrosion resistance, mechanical strength and high temperability, make them effective for working un- der critical conditions.

$2.25 \mathrm{Cr}-1 \mathrm{Mo}$ steels have a stable microstructure with fine carbides that prevent the movement of grain contour disagreements, thus increasing their mechanical strength. However, it is inevitable that during severe working conditions, microstructural changes will occur causing loss of strength of the

*Corresponding author: Juliermes CP, Materials Science Laboratory, UEMA/CESC, Caxias; Mechanical Testing Laboratory, PPGEM/IFPI CEP, Teresina; Department of Metallurgical and Materials Engineering, UFC, Fortaleza, Brazil

Accepted: September 21, 2019; Published: September 23, 2019

Copyright: (C) 2019 Juliermes CP, et al. This is an open-access article distributed under the terms of the Creative Commons Attribution License, which permits unrestricted use, distribution, and reproduction in any medium, provided the original author and source are credited.

Juliermes et al. Int J Metall Met Phys 2019, 4:040 
material, thus compromising its efficiency in service, these modifications include: carbide transformation, precipitation and decomposition of perlite and bainite areas [1]. Still in service, the tensile properties of these materials used in nuclear and thermal power plant components are degraded over time, therefore their altered tensile properties should be known for service life assessment. Therefore, the determination of tensile properties of materials using miniaturized sample techniques has been an active area of research [2].

Thus, to reduce the problems caused to the $2.25 \mathrm{Cr}-1 \mathrm{Mo}$ steels at high temperatures, suitable heat treatments are applied, where the chemical composition and the cooling rate are important parameters to obtain an optimal microstructure and, consequently, the optimization of mechanical properties such as tensile strength and high hardness [3].

Quenching is a type of heat treatment consisting of heating the material within the austenitic field ( $\gamma$ phase), followed by rapid cooling, thus avoiding diffusional transformations and thus obtaining martensitic phase, providing high hardness and greater resistance mechanical. However, stresses caused by martensitic transformations can cause cracks and distortions in the microstructure, Steel should be reheated at sub-critical temperatures to correct material toughness and excessive hardness [4].

The $2.25 \mathrm{Cr}-1 \mathrm{Mo}$ steels generally have ferritic and pearlitic microstructure, however, other phases are possible to obtain through suitable treatments such as normalization, which is obtained by heating the steel between 1,183 to $1,213 \mathrm{~K}$ and air cooling, resulting in phases composed of ferrite and bainite, another widely used quenching treatment, obtained by heating the material from 1,213 to $1,253 \mathrm{~K}$ with oil cooling followed by tempering at temperatures between 843 to $978 \mathrm{~K}$, resulting in martensitic and bainitic phase [5].

The final mechanical properties and their evolution at operating temperature are highly influenced by carbides. In the general case of a martensitic or bainitic steel, carbide precipitation may occur during austenite decomposition, after cooling, or after subsequent tempering. In $2.25 \mathrm{Cr}$-1Mo steels, several carbides may coexist, such as $M_{3} C, M_{2} C$, $M_{7} C_{3}, M_{23} C_{6}$ and $M_{6} C$, these carbides are probably observed, in the order of their thermodynamic stability [6].

According to Sylvain, et al. [7] the initial quenching by steelmakers as well as additional fabrication heat treatments such as dehydrogenation treatment (DHT), intermediate stress relieving treatments (ISR) or final post weld heat treatment (PWHT) should be performed, very carefully, as the final properties of typical steel pressure vessels are not only a function of their chemical composition, but also a function of all heat treatments performed during manufacture.

Therefore, in order to guarantee the operation at high temperatures of equipment based on these materials, it is essential to maintain a stable microstructure, so the study of heat treatment cycles, followed by possible microstructural transformations and carbide precipitation is of great importance in predicting the estimated useful life of these components.

Within this context, the present work intends to contribute to the theme, by studying the effects of the quench hardening process on the microstructure and mechanical properties of $2.25 \mathrm{Cr}-1 \mathrm{Mo}$ steel, thus obtaining results that optimize this material and also improve the technical feasibility of its use and maintenance.

\section{Materials and Methods}

The base material of this research was $2.25 \mathrm{Cr}$ $1 \mathrm{Mo}$ steel, supplied by Arcelor Mittal Industry, in standardized condition (SC), its chemical composition by weight according to ASTM standard A387 grade 22 [8] is given by Table 1.

A total of eight cylindrical specimens $(25 \mathrm{~mm}$ in length and $6 \mathrm{~mm}$ in diameter) with threaded end system for proper test adaptation were machined as recommended by NBR ISO 6892 [9]. Four samples were separated and the others four were subjected to the following heat treatment condition: Austenization at $1223 \mathrm{~K}$ for $2 \mathrm{~h}$ in an argon muffle furnace followed by rapid cooling in mineral oil, followed by tempering at $773 \mathrm{~K}$ for $2 \mathrm{~h}$ and air-cooled. Austenization temperature was chosen based on

Table 1: Chemical composition of steel $2.25 \mathrm{Cr}-1 \mathrm{Mo}(\%$ weight).

\begin{tabular}{|l|l|l|l|l|l|l|}
\hline C & Mn & P & S & Si & Cr & Mo \\
\hline 0.15 & 0.15 & 0.15 & 0.005 & 0.05 & 2.25 & 1.05 \\
\hline
\end{tabular}




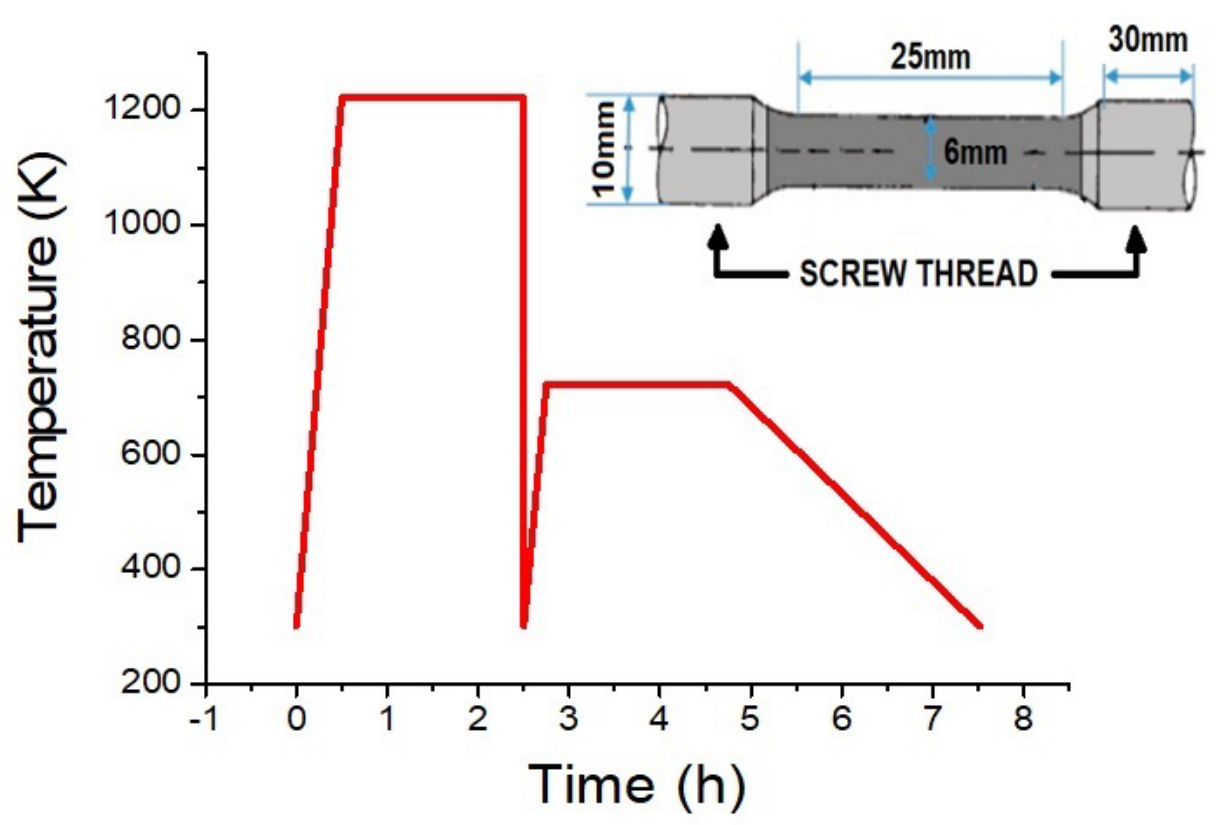

Figure 1: Heat treatment cycle of the $2.25 \mathrm{Cr}$-1Mo steel and specimen model.

the time, temperature and transformation (TTT) diagram of the $2.25 \mathrm{cr}-1 \mathrm{mo}$ steel as reported by some authors [10-12]. Figure 1 illustrates the heat treatment cycle of the material and attached the illustrative diagram of the specimen.

After being treated and mechanically tested, the specimens were cut in the region corresponding to the portion useful for metallographic preparation according to ASTM E 3-01 [13]. To reveal the microstructure of the samples, chemical attacks with $2 \%$ Nital reagent were used. For each phase, LePera reagent $(1 \mathrm{~g}$ of sodium metabisulphite in $100 \mathrm{ml}$ of water and $4 \mathrm{~g}$ of picric acid in $100 \mathrm{ml}$ was used ethanol) and to enhance the grain boundaries of the martensitic matrix, Picral reagent $(6 \mathrm{~g}$ picric acid, $3 \mathrm{ml} \mathrm{HCl}, 100 \mathrm{ml}$ ethyl alcohol and $100 \mathrm{ml}$ distilled water) was used.

Then the samples were analyzed using Olympus GX 51S optical microscopy (OM) and JXA 840A scanning electron microscopy (SEM). The quantification of the present phases was obtained through micrographs processed with the aid of the ImageJ image analyzer. The carbides characterization was performed by the Berzélius solution dilution method and filtered to extract the precipitates present in each sample and thus identified by Siemens D5000 X-Ray diffraction with copper tube $(\lambda=1.54 \AA$ ).

The response to mechanical performance was evaluated by Vickers microhardness tests with the aid of a SHIMADZU Model HMV2 microdurometer, being tested according to ASTM E384 - 72 [14] in samples of the starting material and after heat treatment with a load of $0.1 \mathrm{Kgf}$ for $30 \mathrm{~s}$ in order to reach the maximum deformation caused by the indentation corresponding to the applied load, forming indentations spaced approximately 300 $\mu \mathrm{m}$. To determine the size of the grain, the Heyn methodology of ASTM E112-96 [15] was used in micrographs processed by the ImageJ software.

Finally, eight tensile tests (4 standardized condition sample and 4 quenching-treated samples) were performed according to ASTM E - 21 [16] through an INSTRON model 8802 machine with built-in heating oven, the 8 specimens were tested at temperatures of $300,773,873$, and $973 \mathrm{~K}$ with a traction speed of $0.5 \mathrm{~mm} / \mathrm{min}$.

\section{Results and Discussion}

\subsection{Cr-1Mo steel microstructure standardized condition}

The microstructure obtained by optical microscopy of the $2.25 \mathrm{Cr}-1 \mathrm{Mo}$ steel at the starting condition (SC) and attacked with Nital $2 \%$ can be observed in Figure $2 \mathrm{a}$ and Figure $2 \mathrm{~b}$. The material has a biphasic microstructure with $65 \%$ bainite (indicated by the letter B) with darker color and 35\% ferrite (indicated by the letter F) with larger and lighter grains. According to the optical micrographs analysis using ImageJ software and application of 


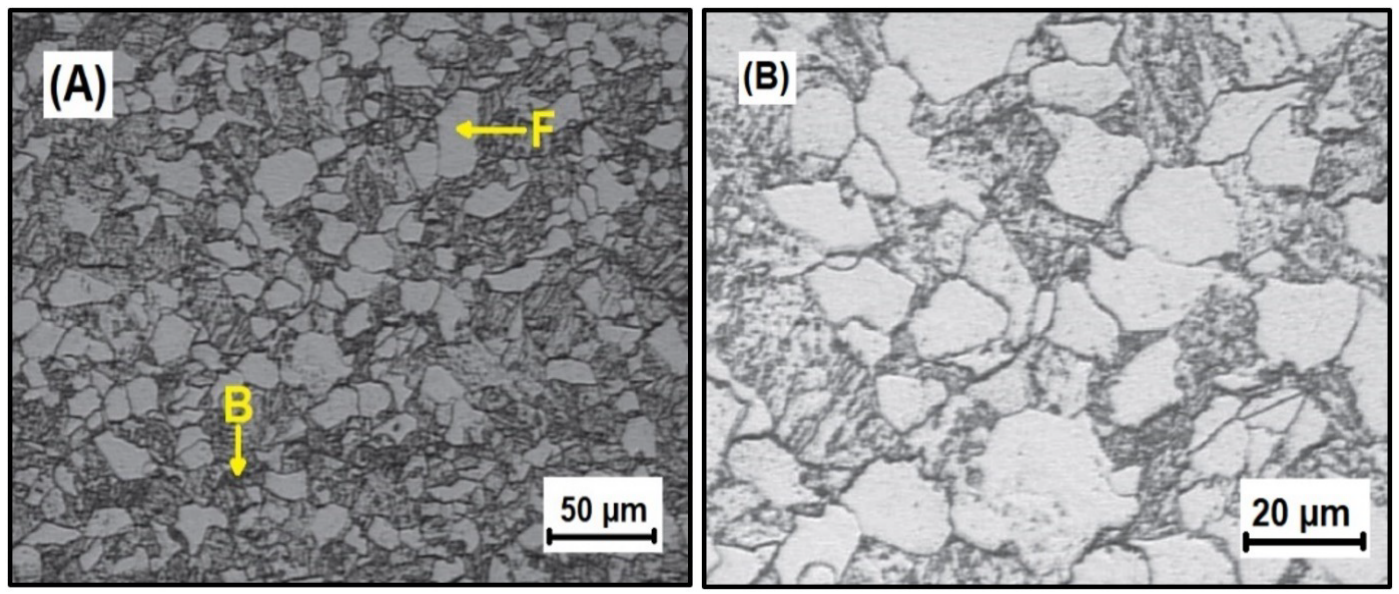

Figure 2: Steel 2.25Cr-1Mo optical microscopy standardized condition (SC): a) 200X magnification; b) 600X magnification.
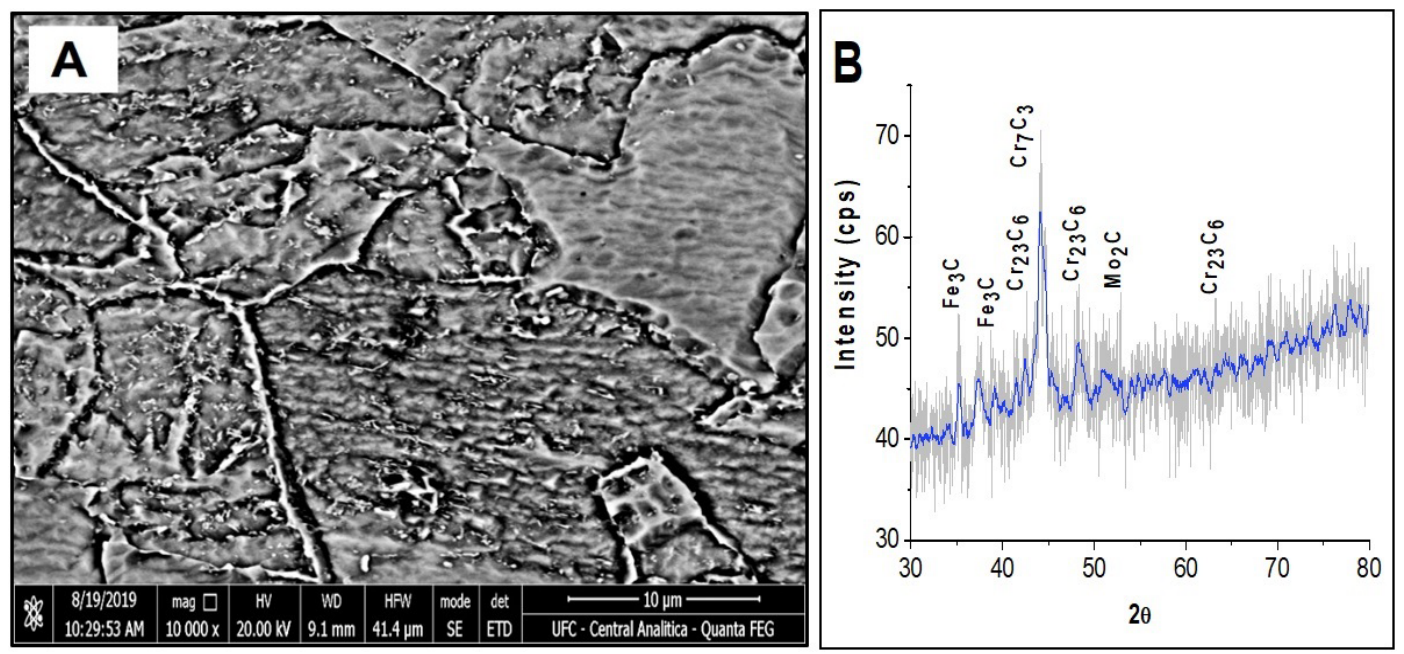

Figure 3: a) SEM of the steel in the standardized condition (SC); b) X-ray diffractogram of the material in the starting condition.

Heyn methodology, ferritic grains were identified and quantified in approximately $30 \pm 8 \mu \mathrm{m}$.

The microstructure presented by the $2.25 \mathrm{Cr}$ $1 \mathrm{Mo}$ steel in the initial condition is typical of the manufacturing process, being similar to the microstructures of the same Normalized material reported in the research by Acarer, et al. [3].

Figure 3a shows the SEM micrograph of the 8300X magnifying starting material, it is possible to notice some needle-shaped, circular carbides and rods distributed inside the bainite and ferrite. Figure $3 b$ shows the $X$-ray pattern for the sample in the standard condition and Smoothing technique was used to remove signal noise. According to the analyzes obtained, it was possible to characterize the $\mathrm{Fe}_{3} \mathrm{C}$ carbide known as cementite which is characteristic of perlite microstructure, and also $\mathrm{M}_{2} \mathrm{C}$ carbides rich in molybdenum, chromium rich $\mathrm{M}_{7} \mathrm{C}_{3}$ and $\mathrm{M}_{23} \mathrm{C}_{6}$ most often presenting high levels of iron, chromium and molybdenum. Generally, the number and size and shape of precipitates are associated with the mechanical properties of ferritic steels [17].

Joarder, et al. [18] in their research on the microstructural degradation of $1.25 \mathrm{Cr}-0.5 \mathrm{Mo}$ steel, characterized the Normalized samples and showed the presence of $\mathrm{M}_{2} \mathrm{C}$ carbides in the form of ferritic matrix and $\mathrm{M}_{23} \mathrm{C}_{6}$ carbides in irregular shapes located along the grain contours.

\subsection{Cr-1Mo steel microstructure quenched and tempered}

Figure 4a shows the optic micrograph of the ma- 


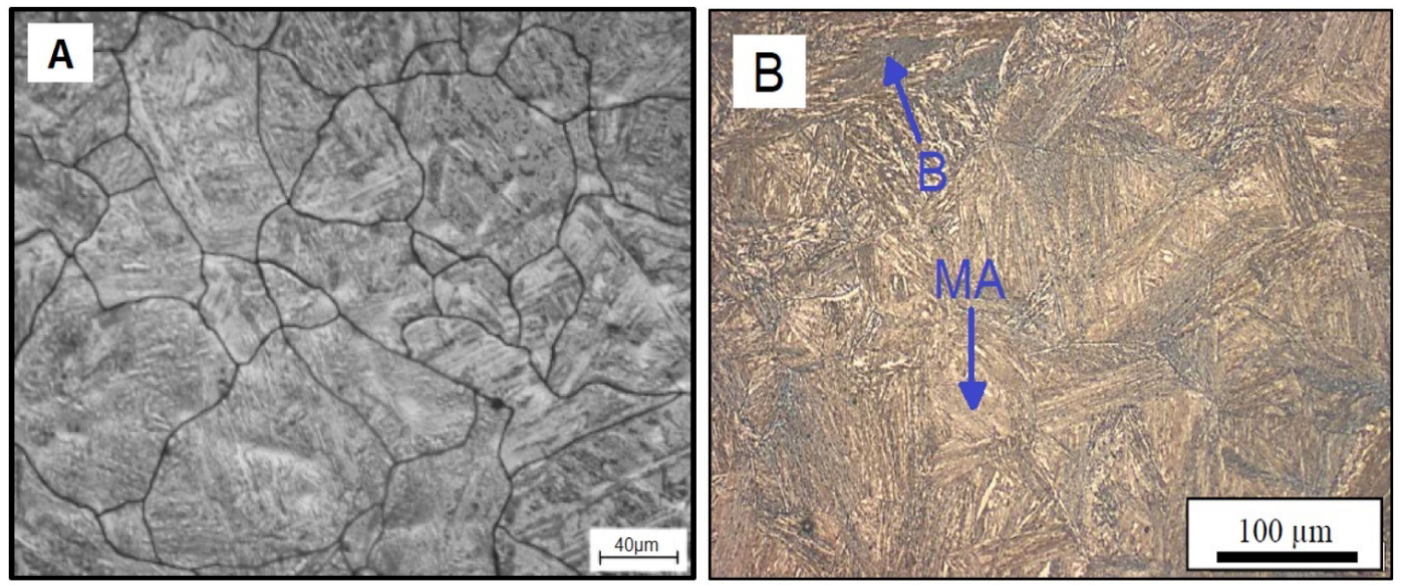

Figure 4: Optical microscopy of steel 2.25Cr-1Mo quenched and tempered (QT): a) Nital attack and picral reagent at 200X; b) 500X Lepera reagent attack.
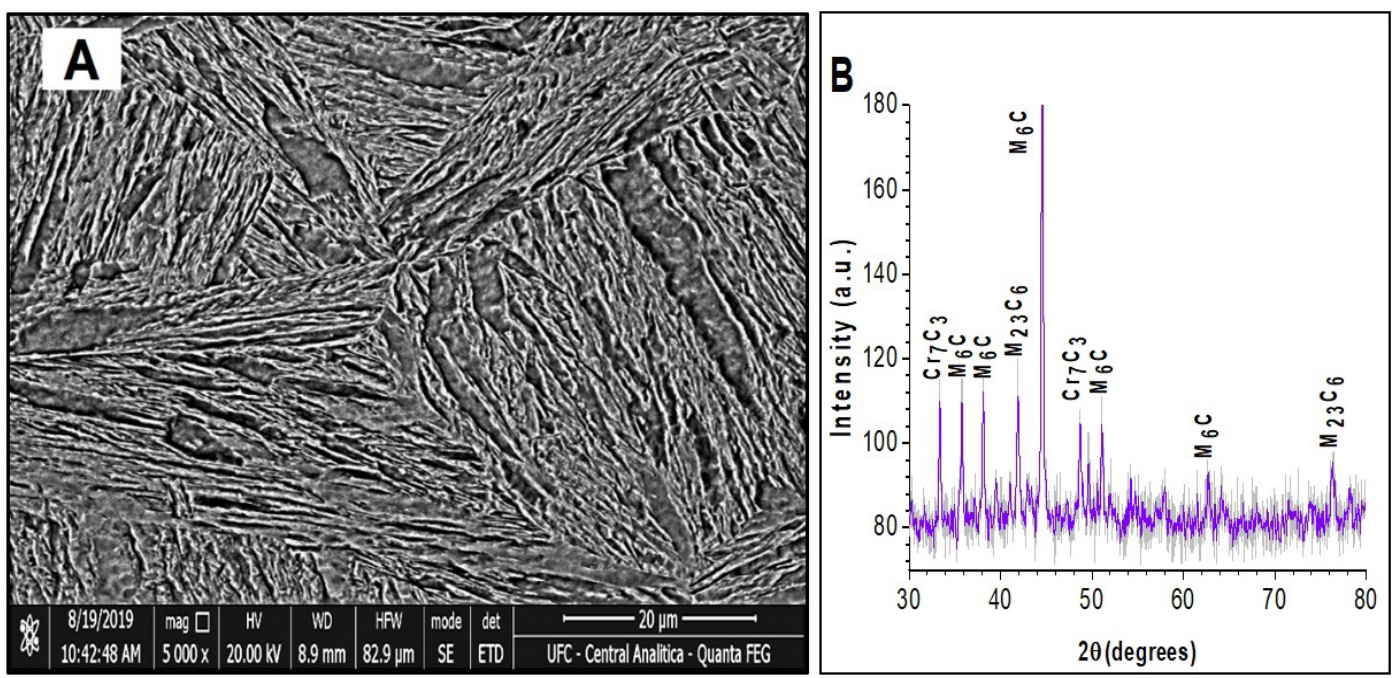

Figure 5: SEM micrograph of steel $2.25 \mathrm{Cr}$-1Mo quenched and tempered (QT): a) With $2 \%$ Nital attack with $5000 \mathrm{X}$ increases; b) X-ray diffractogram of treated material.

terial quenched and tempered (QT) and attacked with $2 \%$ Nital, it is possible to notice the formation of martensitic phase arranged in the form of very thin needles grains in this sample. The microstructure obtained was already expected, because according to the time, temperature and phase transformation (TTT) diagram of steel $2.25 \mathrm{Cr}$ - $1 \mathrm{Mo}$, the abrupt cooling of the material would lead to this specific phase.

Figure $4 \mathrm{~b}$ shows the microstructure attacked with LePera reagent, where the martensitic phase with retained austenite (MA) is lighter shaded and a bainitic phase (B) with darkened contrast, both phases have approximate proportions $85 \%$ and $15 \%$ respectively.

Through the observed structures, it was possi- ble to notice that the heat treatment influenced the final microstructure of the material. For this condition, the martensitic microstructure obtained is a metastable phase with body-centered tetragonal structure (CBT), which is a distorted shape, therefore, resulting from the transformation of austenite. The microstructure of this work is similar to the $2.25 \mathrm{C}-1 \mathrm{Mo}$ steel observed in Costa research [19], in his study of the susceptibility to hydrogen embrittlement of the $2.25 \mathrm{Cr}-1 \mathrm{Mo}$ steel joint, where the author reports micrograph with martensitic microstructure.

The quenched and tempered (QT) sample had a grain size equivalent to $176 \mu \mathrm{m}$, compared to the sample grain size as received, we realized that the heat quenching treatment increased the grain size. 
According to Oliveira, et al. [20], grain growth is a thermally activated phenomenon, motivated by the decrease in the surface energy of grain boundaries, where factors such as time, temperature, solute atoms, precipitate particles can influence different shapes and sizes.

Figure $5 a$ shows the SEM micrograph of the material quenched and tempered (QT) attacked with Nital $2 \%$ reagent with $5000 X$ magnification. It shows the highest definition martensitic slats and a circulate carbides dispersed in martensitic and others of ultra-fine grain size in grain outlines. Figure $5 b$ shows an analysis of the X-ray diffraction pattern and the Smoothing technique was used to remove signal noise and thus it was possible to characterize the carbides present in the treated samples. For this technique it was possible to identify the presence of chromium-rich $\mathrm{M}_{7} \mathrm{C}_{3}$ carbides, the $\mathrm{M}_{23} \mathrm{C}_{6}$ carbide containing iron, chromium and molybdenum and $\mathrm{M}_{6} \mathrm{C}$ carbide in large quantities in a simple ternary system.

$\mathrm{M}_{6} \mathrm{C}$ carbide is mainly iron and molybdenum carbide, and may have relatively high levels of other elements, such as silicon, appearing in globular and nucleic form in the grain boundaries at the matrix-carbide interface, thus being carbide, more stable end after long time exposure to creep [5].

According to CESCON research [21], $\mathrm{M}_{6} \mathrm{C}$ carbide is stabilized by the presence of tungsten, silicon, nitrogen, oxygen and niobium and its presence contributes significantly to the abrasion resistance of fast steels due to its high hardness.

Research by Wang, et al. [22], shows the effects of heat treatments on $9 \mathrm{Cr}-0.5 \mathrm{Cr}$ martensitic steels through optical microscopy and transmission electron microscopy, proving the strengthening attributed to the martensitic phase by precipitation of $\mathrm{M}_{23} \mathrm{C}_{6}, \mathrm{M}_{6} \mathrm{C}$ nitrides and carbides $\mathrm{e}$ $\mathrm{MX}$ carbonitrides.

Bhadeshia [23], reports that the tensile strength and creep in steel $2.25 \mathrm{Cr}$ - $1 \mathrm{Mo}$ is due to a fine precipitation of carbides, which vary according to temperature and service life; these are initially $\mathrm{Fe}_{3} \mathrm{C}$ carbides and $\mathrm{M}_{2} \mathrm{C}$ carbides which then evolve to $\mathrm{M}_{23} \mathrm{C}_{6}, \mathrm{M}_{7} \mathrm{C}_{3}$ e $\mathrm{M}_{6} \mathrm{C}$.

\section{Steel hardness testing $2.25 \mathrm{Cr}-1 \mathrm{Mo}$}

Vickers microhardness tests of the material in both conditions were plotted on the graph of Figure $6 \mathrm{a}$, in standardized condition (SC), the material showed an average of $184 \pm 18 \mathrm{HV}$, the high standard deviation, can be explained by the microhardness differences between the ferritic and bainitic phases, the Figure $6 \mathrm{~b}$ shows a and specific micro indentation in a ferritic grain.

These values are very close to the results obtained in Pinheiro researches [24], reporting for Steel $2.25 \mathrm{Cr}-1 \mathrm{Mo}$ in the standardized condition and with a Vickers microhardness ranging from 176 to $182 \mathrm{HV}$.

For the Quenched and Tempered (QT) sample, the average value for microhardness was $388 \pm 4$ $\mathrm{HV}$, comparing the results with the starting material, it is possible to notice that the microstructural transformation induced by the quench heat treatment caused an increase in the hardness Vickers microhardness from 184 to $388 \mathrm{HV}$. The increase in martensite hardness can be attributed to the fol-
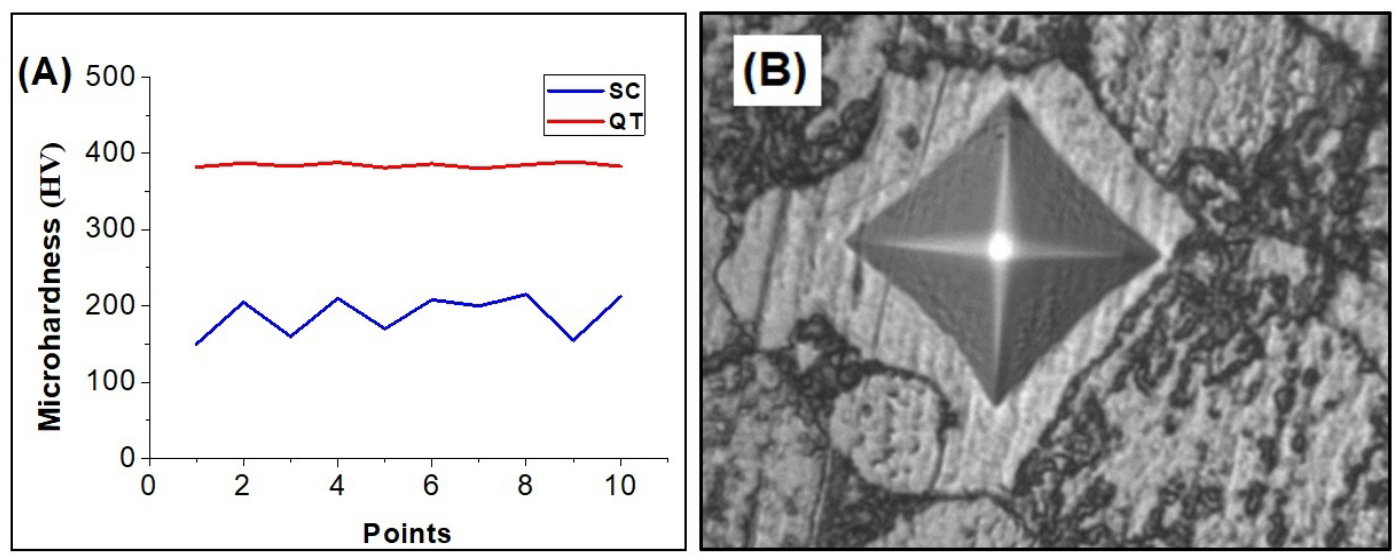

Figure 6: a) Vickers microhardness tests of the samples (SC) and (QT); b) Microstructure with a punctual micro indentation in the ferritic grain. 


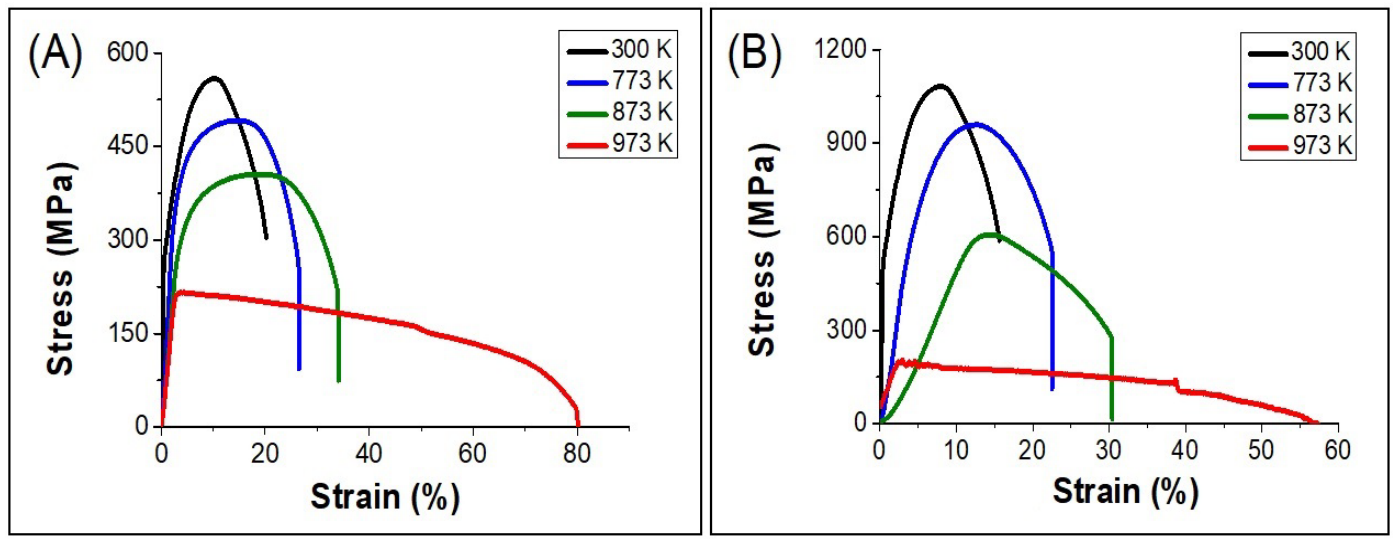

Figure 7: 2.25Cr-1Mo steel tensile testing: a) SC; b) QT.

lowing factors: Precipitation hardening, grain size effect and substructure hardening [25].

Studies on the hydrogen permeability of $2.25 \mathrm{Cr}$ $1 \mathrm{Mo}$ steel, reported by Parvathavarthini, et al. [26], show that Vickers microhardness tests of this hardened material generally have hardness averaging $372 \mathrm{HV}$. This small microhardness divergence, compared to this research, can be explained by differences in treatment parameters, such as: time in Austenization temperature, cooling medium and heat gradient.

\section{Steel tensile testing $2.25 \mathrm{Cr}-1 \mathrm{Mo}$}

The characteristic curves of the tensile tests of the eight specimens under the standardized conditions (SC) and Quenched and Tempered (QT), tested at temperatures of $300,773,873$ and $973 \mathrm{~K}$ with a strain rate of $0.5 \mathrm{~mm} / \mathrm{min}$ are plotted in Figure $7 \mathrm{a}$ and Figure $7 \mathrm{~b}$ respectively. All tensile tests were conducted below Line AC1 (1,072 to 1,094 K) of the time, temperature and phase transformation diagram (TTT) of steel 2,25Cr-1Mo. During the material heating, only above the AC1 line, phase transformations are possible, thus the ferrite transformation into austenite [27].

According to the traction curves, it is possible to notice that in all tests performed, the increase in temperature caused a reduction in the tensile strength levels of the specimens, followed by an increase in the materials ductility. This behavior was already expected, because at high temperatures, the grains of a polycrystalline metal can move relative to each other through the shear process that occurs in the grain contours, and thus favored by the increase in temperature [28].

The specific results of tensile test such as Tem-
Table 2: Results of steel tensile data $2.25 \mathrm{Cr}-1 \mathrm{Mo}$ in standardized conditions (SC) and Quenched and Tempered (QT).

\begin{tabular}{|l|l|l|l|l|l|l|}
\hline Amostra & $\begin{array}{l}\text { T } \\
\text { (K) }\end{array}$ & $\begin{array}{l}\text { EM } \\
\text { (MPa) }\end{array}$ & $\begin{array}{l}\text { YS } \\
\text { (MPa) }\end{array}$ & $\begin{array}{l}\text { TSL } \\
\text { (MPa) }\end{array}$ & $\begin{array}{l}\text { TE } \\
\text { (\%) }\end{array}$ & $\mathbf{n}$ \\
\hline SC1 & 300 & 210,200 & 442 & 558.2 & 20.2 & 0.14 \\
\hline SC2 & 773 & 168,955 & 370 & 490.8 & 26.5 & 0.11 \\
\hline SC3 & 873 & 126,500 & 335 & 405.4 & 34.1 & 0.06 \\
\hline SC4 & 973 & 73,100 & 180 & 215.1 & 80.1 & 0.04 \\
\hline QT1 & 300 & 66,650 & 800 & $1,080.8$ & 17.2 & 0.85 \\
\hline QT2 & 773 & 53,500 & 780 & 946.5 & 22.5 & 0.64 \\
\hline QT3 & 873 & 11,000 & 550 & 606.7 & 30.4 & 0.60 \\
\hline QT4 & 973 & 7,850 & 175.9 & 198.7 & 57.3 & 0.41 \\
\hline
\end{tabular}

perature (T), Elastic Modulus (EM), Yield Stress (YS), Tensile Strength Limit (TSL), Total Elongation (TE), and Hardening ( $n$ ) tested at temperatures $(300,773,873$ and $973 \mathrm{~K}$ ) for $2.25 \mathrm{Cr}$-1Mo steel are shown in Table 2. The modulus of elasticity was calculated through equation 01 , and applied in the linear region, where Hooke's law is valid.

$$
E M=\frac{d \sigma}{d \varepsilon}
$$

Where $\sigma$ is the stress in MPa and $\varepsilon$ is the percent strain. It is possible to notice that the modulus of elasticity (EM) presents higher values when tested at $300 \mathrm{~K}$, where they show with greater fragility state, presenting $210,200 \mathrm{MPa}$ for the samples (SC1) and $66,650 \mathrm{MPa}$ for the sample (QT1), these values fall with increasing test temperature in both treatment conditions, highlighting the sample (QT4) with modulus of elasticity equivalent to $7,850 \mathrm{MPa}$. The results of this research corroborate the data of Lescano 
and Silvetti [29], where the increase of the tensile test temperature causes a strong reduction in the modulus of elasticity, reaching $10 \%$ reduction at $473 \mathrm{~K}$ and $20 \%$ at $773 \mathrm{~K}$ relative to ambient temperature.

Evaluating the yield stress (YS) and resistance limit (TSL) behavior, the data show that for temperate condition, the sample (QT1) presented better performance, with yield strength of $800 \mathrm{MPa}$ and Resistance Limit 1,080.8 MPa, followed by the Sample (SC1) in standardized conditions, with yield stress at $442 \mathrm{MPa}$ and Resistance Limit of 558.2 $\mathrm{MPa}$, both samples are typical of hardened material. The other tests show a drop in these two properties with the increase of the test temperature, thus presenting lower mechanical efficiency, highlighting the sample (QT4) tested at $973 \mathrm{~K}$ with yield stress of $175.9 \mathrm{MPa}$ and limit of resistance of 198.7 MPa. The drop in these values for this particular sample can be attributed to the microstructural evolution of martensite during high test temperatures, where carbide and slat coalescence resulted in a reduction in mechanical strength. Still for the sample (QT4), a discontinuous flow was observed followed by an increase in the ductility of the material, this phenomenon was also reported by Rizzia, et al. [30], noting a curve characterized by aliasing, known as the Portevin-Le-Chatelier effect which is influenced by the field of internal stresses created during hot tensile tests. This ambiguous behavior of these two properties was also confirmed in the research by Dette, et al. [31], reporting that, keeping the strain rate constant for tensile tests performed on $2.25 \mathrm{Cr}$-1MoNiNb Ferritic steel, the yield strength and the yield strength the traction decreases as the temperature increases.

Regarding the results of the total elongation, it was possible to notice that for standardized (SC) and Quenched and Tempered (QT) conditions, the samples (SC1) and (QT1) respectively presented lower ductility when compared to the other tests. presenting respectively $20.2 \%$ and $17.2 \%$ of elongation, being, therefore, well characteristic of tests that suffer the phenomenon of cold deformation. For the other tests, an increasing behavior of this property is observed as a function of the temperature increase, highlighting the sample (SC4) tested at $973 \mathrm{~K}$ presenting $80.1 \%$ of elongation, followed by the sample (QT4) also tested at $973 \mathrm{~K}$ with $57.3 \%$ extension. These results were expected, given that the greater the elongation, the greater the plastic deformation and, consequently, the greater the ductility of the material. This trend was also observed by Changsheng, et al. [32] where the authors found that the increase in temperature causes the increase in elongation values and reduction of material area, provided that there is no phase transformation during the tests.

Regarding the behavior of the material in the hardening factor, it was determined through the Hollomom ratio (Equation 2), applied at the point of greatest load $\left(\sigma_{\max }\right)$.

$$
\bar{\sigma}=k \varepsilon^{n}
$$

Where $\sigma$ is the maximum load (MPa), $K$ is the strength coefficient of the material and $n$ is the hardening coefficient. According to Table 2, it is observed that this property decreases with increasing temperature, mainly samples (SC1) and (QT1), both under specific conditions and tested at $300 \mathrm{~K}$, which are more hardened, with $\mathrm{n}=0.14$ and $\mathrm{n}=$ 0.84 respectively and the least hardened was the (SC4) sample tested at the highest temperature (973 K) with $n=0.04$.This decrease in hardening values was also expected, given that the increase in the test temperature facilitates the movement of disagreements between grain contours and these interact with each other or with other imperfections and obstacles [33].

Cardoso, et al. [34], researched on the microstructural degradation due to oxide layer in $2.25 \mathrm{Cr}$-1Mo steel tubes used in boilers, in the study, tensile tests showed that at $300 \mathrm{~K}$ tube 2 (material with $130 \mu \mathrm{m}$ of oxide layer) presented higher strength (475 $\mathrm{MPa}$ ) and also higher hardness $(155 \mathrm{Hv})$ than tube 1 (new material), this fact was related to the increase of the amount of precipitates of type $\mathrm{M}_{2} \mathrm{C}$. However, when tested at $873 \mathrm{~K}$, the presence of coarser precipitates at the grain boundaries contributed to reduce the material strength to $150 \mathrm{MPa}$ and reduced hardness to $140 \mathrm{Hv}$.

Pereira, et al. [35], reported the effects of annealing heat treatment on the microstructure and mechanical properties of $2.25 \mathrm{Cr}$-1Mo Ferritic steel, they characterized for the treated material a microstructure with $80 \%$ ferrite and $20 \%$ grain perlite in $45 \mu \mathrm{m}$ and average hardness $73.6 \mathrm{HBR}$. Tensile tests showed that Strength Limit (TSL) values led to a decrease of $650 \mathrm{MPa}$ when tested at $300 \mathrm{~K}$ to 153 $\mathrm{MPa}$ when tested at $973 \mathrm{~K}$. The samples presented 

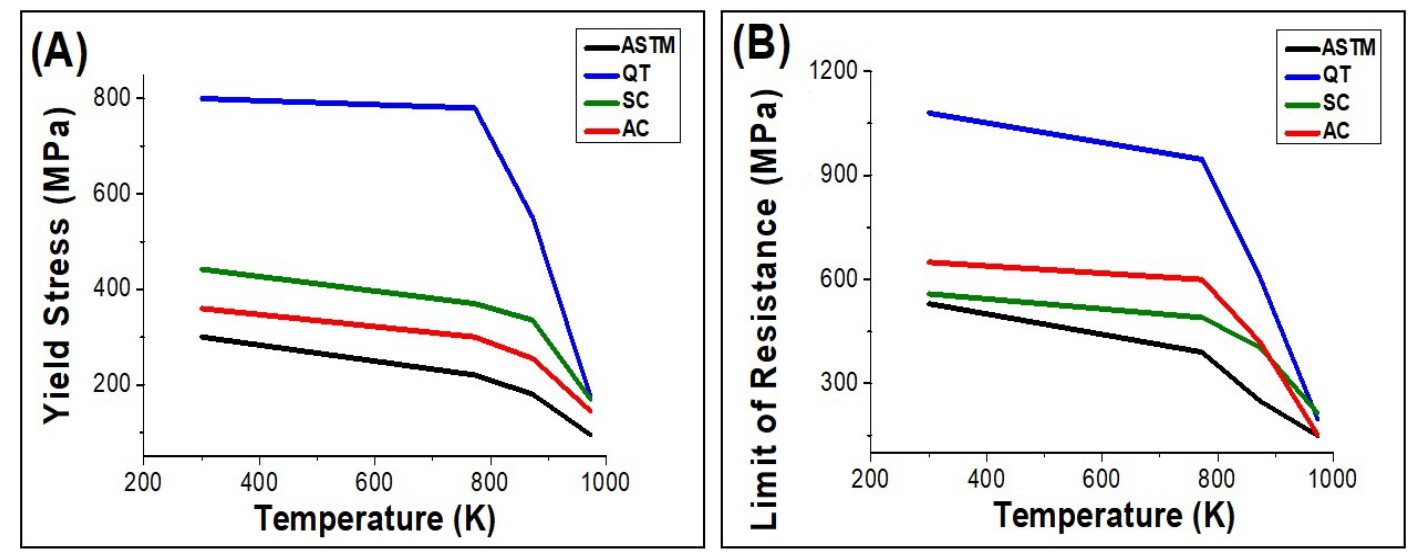

Figure 8: Comparison of yield stress, steel strength limit 2.25Cr-1Mo versus ASTM DS6S2, Quenched and Tempered (QT), Standardized Conditions (SC) and annealed conditions (AC).

an area reduction of $68 \%$ and $95 \%$ for these two temperature levels.

Figure 8a and Figure 8b illustrates comparative data on yield strength (YS) and strength limit (TSL) of $2.25 \mathrm{Cr}$-1Mo steel under various possible microstructural: Standardized Conditions (SC), Quenched and Tempered (QT) of this work, in the Annealed condition (AC) studied by Pereira, et al. [35] and with the data required by ASTM DS6S2 [36].

The yield stress results reproduced much of the tendency of the behavior observed in the Resistance limit results for each analyzed condition. However, the yield stress levels as well as the strength limits of the $2.25 \mathrm{Cr}$-1Mo steel in quenched and tempered (QT) conditions show that their performance is much higher compared to the same material tested in the standard condition (SC), as well as the levels provided by ASTM DS6S2A and also in Annealed (AC) condition.

Comparing the values obtained in the standard condition $(\mathrm{SC})$ in relation to the material in the Quenched and Tempered (QT) condition it is possible to notice that the material showed excellent results, especially at $300 \mathrm{~K}$ where the tensile strength limits increase by 558.2 $\mathrm{MPa}$ to $1,080.8$ $\mathrm{MPa}$, already in the hot tensile tests, the material showed good performance at $773 \mathrm{~K}$ where resistance limit increases from 490.8 MPa to 946.5 $\mathrm{MPa}$ precisely at the temperature where steel is most used, at $873 \mathrm{~K}$ its mechanical efficiency was also very visible, with resistance limit increasing from 405.4 MPa to 606.7 MPa and finally showing no visible performance when tested at $973 \mathrm{~K}$, showing a limit of strength of approximately 198.7 MPA for the treated sample, this result therefore confirms the influence of the test temperature on the mechanical strength of the steel.

Recently, this downward trend in mechanical performance at high temperatures has also been observed in research by Zhonghua, et al. [37], reporting that this type of instability in the mechanical strength of $2.25 \mathrm{Cr}-1 \mathrm{Mo}-0.25 \mathrm{~V}$ occurs during plastic deformation and may be attributed to the phenomenon of dynamic deformation aging (EDD) also suffered by various types of steels depending on parameters such as high temperatures and low deformation rates.

Gupta, et al. [38], observed that in a Cr-Mo-V steel, dynamic aging occurs with the interaction between solute atoms and mobile disagreements and that the mobility of solute atoms depends on the diffusion rate, favored by the high temperature of the hot tensile tests. The time required for interaction to occur is also reduced at elevated temperatures, accentuating the occurrence of instabilities in tests conducted at lower strain rates.

Yan, et al. [39], also observed the loss of mechanical strength for $9-12 \% \mathrm{Cr}$ steel with martensitic microstructure when using slow strain rates, evidencing the evolution of martensitic microstructure at high temperatures, resulting in decreased density of disagreements within martensitic slats.

\section{Conclusions}

The study of the Microstructural and Mechanical Characterization of Quench hardened $2.25 \mathrm{Cr}$ $1 \mathrm{Mo}$ Steel showed that the heat treatment on $2.25 \mathrm{Cr}$-1Mo steel was adequate to obtain the desired microstructure and mechanical properties, the predominant phase was the martensitic with 
$15 \%$ retained austenite. The XRD analysis verified the presence of $\mathrm{Fe}_{3} \mathrm{C}, \mathrm{M}_{2} \mathrm{C}, \mathrm{M}_{7} \mathrm{C}_{3}$ and carbides of the material in the condition as received. For the temperate sample, the presence of $\mathrm{M}_{6} \mathrm{C}$ carbide arranged in the grain contours was decisive for the high hardness of the martensite reaching $388 \mathrm{Hv}$. The quench heat treatment increased the grain size of the treated material from $30 \mu \mathrm{m}$ to $176 \mu \mathrm{m}$. The results of the tensile tests proved that the hardened samples of $2.25 \mathrm{Cr}-1 \mathrm{Mo}$ steel had their mechanical resistance with optimized levels at 300 , 773 and $873 \mathrm{~K}$ where they are more applied in the petrochemical industries, however, mechanical instability is evidenced when tested at $973 \mathrm{~K}$, thus showing poor performance in this specific working condition.

\section{Acknowledgment}

The authors would like to thank UEMA institutions for their academic support, UFPI for their technical support, PPGEM-IFPI for master's degree training, Arcelor Mittal industry for the granting of working material and in particular to UFSCar -DEMA for its institutional partnership and mechanics essays provided.

\section{References}

1. González G, Alessio D, Gualdieri G, Iurman L, Moro $L$ (2012) Evolution of the structure of ferritic steels subjected to torsion. Procedia Materials Science 1: 126-133.

2. Barbadikar DR, Ballal AR, Peshwe DR, Ganeshkumar J, Laha K (2014) A study on the effect of tempering temperature on tensile properties of P92 steel by automated ball indentation technique. Procedia Engineering 86: 910-918.

3. Acarer M, Arici G, Kumdali A, Keskinkilic $S$, Kabakci F (2017) Toughness of 2,25Cr-1Mo steel and weld metal. AIP Conference Proceedings 1877: 090003.

4. Rodrigues JGG, Martinez GB, Bravo VM (2000) Effect of heat treatment on the stress corrosion cracking behavior of 403 stainless steel in $\mathrm{NaCl}$ at $95^{\circ} \mathrm{C}$. Materials Letters 43: 208-214.

5. Baker RG, Nutting J (1959) The tempering of $21 / 4 \%$ $\mathrm{Cr}-1 \% \mathrm{Mo}$ steel after quenching and normalizing. J of The Iron and Steel Institute.

6. Pillot S, Chauvy C, Corre S, Coudreuse L, Gingell A, et al. (2013) Effect of temper and hydrogen embrittlement on mechanical properties of $2.25 \mathrm{Cr}$-1Mo steel grades. International Journal of Pressure Vessels and Piping 110: 17-23.
7. Sylvain D (2015) Microstructural evolution of a $2.25 \mathrm{Cr}-1 \mathrm{Mo}$ steel during austenitization and temper: Austenite grain growth, carbide precipitation sequence and effects on mechanical properties. Materials Ecole National Superior des Mines de Paris.

8. (1990) Standard specification for pressure vessel plate, alloy steel, chromium-molybdenum. ASTM A-387, 257-259.

9. (2002) Metallic materials-room temperature tensile testing. Brazilian Association of Technical Standards (ABNT) - NBR-ISO-6892.

10.Bueno LDe Oliveira, Sordi VL, Marino L (2005) Constant load creep data in air and vacuum on $2.25 \mathrm{Cr}$ 1 Mo steel from $600{ }^{\circ} \mathrm{C}$ to $700{ }^{\circ} \mathrm{C}$. Mat Res 8: 401-408.

11.Ferreira ILS (2013) Hydrogen-microstructure interaction and mechanical properties of 2,25Cr-1Mo steel with and without aging. COPPE, Research institute in Rio de Janeiro, Brazil.

12. Rigueira G, Furtado HC, Lisboa MB, Almeida LH (2011) Evolução microestrutural e alteração de dureza na bainita e na perlita em aços 2,25Cr1Mo após tratamento de envelhecimento. Material 16: 857867.

13.(2011) Standard practice for preparation of metallographic specimens. ASTM.

14.(2011) Standard methods for microhardness vickers of material. ASTM E384 - 72, 559-579.

15.(2000) Standards test methods for determining average grain size. ASTM E-112-96, 3.

16.(1988) Standard practice for elevated temperature tension tests of metallic materials. ASTM E-21, 190196.

17.Jang KN, Kim TK, Kyu K (2019) The effect of cooling rates on carbide precipitate and microstructure of 9CR-1MO oxide dispersion strengthened (ODS) steel. Nuclear Engineering and Technology 51: 249-256.

18.Das SK, Joarder A, Mitra A (2004) Magnetic barkhausen emissions and microstructural degradation study in $1.25 \mathrm{Cr}-0.5 \mathrm{Mo}$ steel during high temperature exposure. NDT \& E International 37: 243-248.

19. Costa LRO (2011) Susceptibility to hydrogen embrittlement of welded steel joint 2,25Cr-1Mo. Rio de Janeiro.

20.Oliveira VB, Sandim HRZ, Raabe D (2017) Abnormal grain growth in Eurofer-97 steel in the ferrite phase field. Journal of Nuclear Materials 485: 23-38.

21.Cescon T (1990) Development and characterization of niobium-containing fast steel from the $\mathrm{M} 2$ steel 
matrix. University of São Paulo, São Paulo, Brazil, 237.

22.Wang SS, Peng DL, Chang L, Hui XD (2013) Enhanced mechanical properties induced by refined heat treatment for $9 \mathrm{Cr}-0.5 \mathrm{Mo}-1.8 \mathrm{~W}$ martensitic heat resistant steel. Materials \& Design 50: 174-180.

23. Bhadeshia HKDH (2001) Bainite in steels, transformations, microstructure and properties. ( $\left.2^{\text {nd }} E d n\right)$, Thomson RC.

24.Pinheiro PHM (2017) Study of MIG/MAG welding applied to the repair of $\mathrm{Cr}-\mathrm{Mo}$ and $\mathrm{Cr}-\mathrm{Mo}-\mathrm{V}$ steels using the double layer-controlled deposition technique. Technology Center, Federal University of Ceará, Brazil.

25.Smith WF (1993) Structure and properties do engineering alloys. ( $2^{\text {nd }}$ edn), McGraw-Hill, Singapore.

26.Parvathavarthini N, Saibaba S, Dayal RK, Khatak HS (2001) Studies on hydrogen permeability of $2.25 \mathrm{Cr}$ 1Mo ferritic steel. Journal off Nuclear Materials 288: 187-196.

27.Campos TO (2015) Microstructural characterization of the thermally affected zone of low alloy steel 2.25Cr-1Mo coated with ERNiCrMo-3 and buttered with ER80S-D2. UFRJ/COPPE, Rio de Janeiro, Brazil.

28. Bueno LO, Sobrinho JFR (2012) Correlation between creep and hot tensile behavior for Part 1 : An assessment according to usual relations involving stress, temperature, strain rate and rupture time. Revista Materia 1098-1108.

29. Lescano DE, Silvetti SP (2012) Study of microstructure and tempered martensite embrittlement in AISI $15 b 4$ steel. Procedia Materials Science 1: 134-140.

30.Rizzi E, Hahner P (2004) On the Portevin-Le Chatelier effect: Theoretical modeling and numerical results. International Journal of Plasticity 20: 121-165.

31.Dette M, Hahn H, Nieuwland HCD, Tichler JW (1983) Presentation of properties of the ferritic alloy
2,25Cr-1MoNiNb for steam generator application in FBR systems. Nuclear Engineering and Design 76: 219-232.

32. Changsheng L, Guojun C, Dongge W, Yongkang Z (2018) Effect of precipitates on mechanical properties for annealed $19 \mathrm{Cr}$-2Mo ferritic stainless steel. Procedia Manufacturing 15: 1604-1611.

33. Han YC, Chen XD, Fan ZC, Bu HQ (2015) Influence of second thermal cycle on reheat cracking susceptibility of welding CGHAZ in vanadium-modified 2.25Cr1Mo steel. Procedia Engineering 130: 487496.

34.Cardoso BR, Comeli FW, Santana RM, Furtado HC, Lisboa MB, et al. (2012) Microstructural degradation of boiler tubes due to the presence of internal oxide layer. Journal of Materials Research and Technology 1: 109-116.

35.Pereira JC, Vitor LS, Brandim AS, Barbosa R, Porto JAS, et al. (2018) Effect of annealing heat treatment on the microstructure and mechanical properties of 2,25Cr-1Mo ferritic steel. Brazilian Journal of Vacuum Applications 36: 152-157.

36.(1971) Supplemental report on elevated-temperature properties of chromium-molybdenum steels (An evaluation of $21 / 4 \mathrm{Cr}$-1Mo). ASTM Data Series Publication DS 6S2, Philadelphia, USA.

37.Zhonghua J, Wang P, Dianzhong L, Yiyi L (2019) Influence of the decomposition behavior of retained austenite during tempering on the mechanical properties of 2.25Cr-1Mo-0.25 V steel. Materials Science and Engineering: A 742: 540-552.

38.Gupta C, Chakravartty JK, Banerjee S (2013) Microstructure, deformation and fracture behavior of $\mathrm{Cr}$ Mo-V steels. International Journal of Metallurgical Engineering 2: 142-148.

39. Yan W, Wang W, Shan YY, Yang K (2013) Microstructural stability of $9-12 \% \mathrm{Cr}$ ferrite/martensite heat-resistant steels. Frontiers of Materials Science 7: 1-27. 